\title{
EDUCAÇÃO EM DIREITOS HUMANOS: UM PANORAMA DO COMPROMISSO SOCIAL DA UNIVERSIDADE PÚBLICA
}

\author{
THAIS APARECIDA DIBBERN ${ }^{\prime *}$ \\ ORCID: https://orcid.org/0000-0003-4826-4614 \\ EVANDRO COGGO CRISTOFOLETTI" ** \\ ORCID: https://orcid.org/0000-0001-5178-6451 \\ MILENA PAVAN SERAFIM ${ }^{1 * * *}$ \\ ORCID: https://orcid.org/0000-0002-7541-4182
}

RESUMO: Este artigo busca debater o compromisso social da universidade pública sob a perspectiva da Educação em Direitos Humanos (EDH), identificando alguns desafios que dificultam a concretização da EDH nestas instituições. Metodologicamente, realizou-se uma revisão bibliográfica da literatura científica acerca dos direitos humanos e do ensino superior brasileiro, bem como uma análise das legislações acerca da EDH, buscando compreender como a universidade pública se insere dentro desta temática. Visualiza-se que as universidades públicas ainda precisam enfrentar alguns desafios para que a concretização das propostas da EDH ocorra, tais como os processos de mercantilização da universidade pública e a privatização do ensino superior; a fragilidade da integração entre ensino, pesquisa e extensão; as dificuldades de se estabelecer uma conexão mais sistemática e profícua com os segmentos e classes sociais que se apresentam em situação de vulnerabilidade social e com direitos violados; e as dificuldades na democratização do acesso à universidade.

Palavras-chave: Direitos humanos. Universidade. Compromisso social.

\footnotetext{
'Universidade Estadual de Campinas, Limeira,SP, Brasil.

"Universidade Estadual de Campinas, Campinas, SP, Brasil.

"Mestranda em Ciências Humanas e Sociais Aplicadas pela Universidade Estadual de Campinas (Unicamp) - Brasil. Pesquisadora do Laboratório de Estudos do Setor Público (LESP/Unicamp) e do Observatório de Direitos Humanos da Unicamp. E-mail:< dibbern.thais@gmail.com>.

“* Doutorando e Mestre em Política Científica e Tecnológica pela Universidade Estadual de Campinas (Unicamp) - Brasil. Pesquisador do Laboratório de Estudos do Setor Público (LESP/Unicamp) e do Grupo de Análise de Inovação (GAPI/Unicamp). E-mail:<evandro.coggo@gmail.com>.

** Doutora em Política Científica e Tecnológica pela Universidade Estadual de Campinas (Unicamp) Brasil. Professora Doutora de Administração Pública da Unicamp. Pesquisadora do Laboratório de Estudos do Setor Público (LESP/Unicamp) e do Grupo de Análise de Políticas de Inovação (GAPI/Unicamp).

E-mail:<milenaserafim@gmail.com>.
} 
HUMAN RIGHTSEDUCATION: AN OVERVIEW OF THE PUBLIC UNIVERSITY'S SOCIAL COMMITMENT

ABSTRACT: This paper seeks to discuss the public university's social commitment, from the perspective of Human Rights Education (HRE), identifying some obstacles and challenges that hinder the implementation of HRE. Methodologically, a bibliographical review of the scientific literature on human rights and Brazilian higher education was carried out, as well as an analysis of the legislations on HRE, seeking to understand how the public university inserts itself in this theme. It's seen that public universities still have to face some challenges in order to implement HRE proposals, such as the processes of commodification of the public university and the privatization of higher education; fragility of the integration between teaching, research and extension; the difficulty in establishing a more systematic and fruitful contact between the university and social segments in situation of social vulnerability or violated rights; and, finally, difficulties in the democratization of university access.

Keywords: Human rights. University. Social commitment.

\section{INTRODUÇÃO}

Os debates sobre a pertinência e o compromisso social que as universidades públicas brasileiras assumem perante seu contexto econômico, político, social e cultural abrange diversas matizes teóricotemáticas. Uma destas abordagens refere-se à Educação em Direitos Humanos (EDH), tida como elemento importante para a divulgação, promoção e garantia dos direitos humanos historicamente constituídos e entendida, ela mesma, enquanto um direito a ser concretizado. Com efeito, todos os níveis de ensino são convocados a praticar a EDH de acordo com suas atribuições e particularidades (BRASIL, 2012). Especialmente, as universidades públicas assumem uma função importante nesta questão, pois têm a possibilidade, de acordo com seus pilares, de realizar formação, pesquisa e extensão em direitos humanos, sendo referência cognitiva aos outros níveis de ensino e às outras instituições do sistema superior. Reconhece-se, assim, a relevância do Ensino Superior, bem como a importância social da universidade pública enquanto geradora de uma cultura em direitos humanos.

À vista disso, nosso objetivo consiste em debater o compromisso social da universidade pública sob a perspectiva da $\mathrm{EDH}$ e, a partir disso, identificar alguns entraves e desafios que dificultam a concretização da EDH nestas instituições de ensino. As perguntas que guiaram o estudo são: de que forma a universidade cumpre - ou deveria cumprir - seu compromisso social através da 
EDH? Como ensino, pesquisa e extensão aparecem neste debate? Quais os desafios e tensões que a concretização da EDH enfrenta?

Metodologicamente, o artigo foi desenvolvido através de uma revisão bibliográfica da literatura científica e das legislações acerca da EDH, buscando identificar como o ensino superior, e mais precisamente a universidade pública, se insere dentro desta temática. Incorporou-se a esta revisão, de forma interseccional, alguns estudos acadêmicos que objetivam debater aspectos concernentes à relação entre universidade e sociedade. Em outras palavras, nossa pesquisa buscou encontrar as conexões teóricas entre os debates acadêmicos sobre a EDH e sobre os chamados "compromissos sociais" da universidade pública. Dessa forma, procedemos uma abordagem panorâmica sobre o assunto, procurando destacar os principais pontos desta conexão sem, no entanto, adentrar em algum aspecto específico. Isso porque, para satisfazer às perguntas da pesquisa, foi preciso contextualizar e ampliar o horizonte teórico da EDH nestas instituições, principalmente a fim de compreender os diversos compromissos sociais pelos quais a universidade é impelida a cumprir através dela. Além do mais, a intersecção destes dois "campos teóricos" permitiu identificar alguns desafios que dificultam a concretização e expansão da EDH nas universidades brasileiras.

A pesquisa bibliográfica foi realizada da seguinte forma: buscou-se fazer um levantamento inicial dos artigos, teses, dissertações e legislações sobre a EDH, identificando os principais conceitos e, sobretudo, como estes visualizam o papel do ensino superior e da universidade no processo, bem como seus desafios de implementação. Do outro lado, fez-se o seguinte: levantamento e identificação de pesquisas e estudos sobre a relação entre universidade e sociedade, filtrando aqueles que centraram seus esforços em debater os diversos compromissos sociais que a universidade assume - ou deveria assumir. Por "compromisso social", consideramos o seguinte: os problemas e segmentos sociais dos quais as Instituições de Ensino Superior (IES), sobretudo às universidades públicas, buscam - ou deveriam buscar - contribuir à resolução ou se relacionar, incorporando-os em sua agenda de ensino, pesquisa e extensão.

No primeiro tópico apresentaremos, em linhas gerais, o que é a Educação em Direitos Humanos, contextualizando-a quanto ao seu surgimento e incidência no Brasil. No segundo tópico, partimos da explanação sobre a EDH e o compromisso social da universidade, centrando nosso argumento na ideia de que esta prática educativa se alinha ao compromisso à cidadania e democratização da universidade, 
além de apresentar, panoramicamente, como ela inserir-se-ia no ensino, pesquisa e extensão. No tópico seguinte, de acordo com o debate acumulado, procurou-se indicar alguns desafios da $\mathrm{EDH}$ nas universidades públicas brasileiras. Nesta etapa, considerou-se literaturas que pontuam alguns entraves específicos e, além destas, incorporou-se hipóteses por nós realizadas de acordo com debates acerca da própria situação da universidade pública no Brasil, quais sejam: i. a dificuldade de se incorporar a EDH para além dos cursos de Direito; ii. a debilidade relativa da extensão enquanto função universitária; iii. os processos de privatização do ensino superior e mercantilização da universidade pública; e, conectados a isto, as próprias iv. dificuldades em se democratizar o acesso à universidade.

\section{A EDUCAÇÃO EM DIREITOS HUMANOS}

A Educação em Direitos Humanos se apresenta enquanto uma prática educativa que é tida como uma consequência da decadência das ditaduras militares ao final dos anos 1970, bem como do processo de redemocratização ocorrido nos países latinoamericanos. Fundamenta-se através do reconhecimento, respeito, defesa e promoção do conjunto dos direitos humanos, ${ }^{1}$ possuindo como objetivo desenvolver suas máximas capacidades como sujeitos de direitos e apresentando ferramentas e elementos que podem torná-los efetivos (MAGENDZO, 2006).

De acordo com Benevides (2003), a EDH não se trata apenas da transferência de conhecimentos, mas sim está voltada para uma mudança cultural, baseando-se na transferência e construção de valores através de uma educação permanente, continuada e global. Trata-se de uma formação baseada no respeito à dignidade da pessoa humana, estando orientada para "a mudança no sentido de eliminar tudo aquilo que está enraizado nas mentalidades por preconceitos, discriminação, não aceitação dos direitos de todos, não aceitação da diferença" (BENEVIDES, 2003, p. 1).

Nessa perspectiva, cabe apresentar o horizonte de sentido que perpassa a EDH, o qual fundamenta-se em três dimensões: a primeira dimensão refere-se à formação de sujeitos de direitos, de forma a articular as perspectivas da ética, político-social e práticas concretas; a segunda dimensão diz respeito à oportunização no processo de "empoderamento", no sentido de proporcionar possibilidades e demonstrar a potência de cada ator social, especialmente àqueles que historicamente possuem menos poder nas decisões e processos 
coletivos; e a terceira dimensão refere-se à construção de sociedades verdadeiramente democráticas, de forma a "educar para o nunca mais", isto é, resgatar a memória histórica dos direitos humanos, rompendo com a cultura do silêncio e da impunidade (CANDAU, 2008).

Desse modo, a educação, reconhecida como um dos direitos humanos, vem sendo compreendida como uma ferramenta fundamental para se obter o acesso ao conhecimento histórico dos direitos humanos, assim como permite que a cultura dos direitos humanos seja transmitida de forma a alcançar uma transformação social, integrando valores e noções relativas à cultura da paz, da tolerância e do respeito às diferenças. Em vista disso, a Educação em Direitos Humanos tornou-se parte essencial do conjunto de direitos historicamente constituídos, estando incluída no próprio direito à educação (BRASIL, 2012).

No Brasil, tal direito fora refletido e incorporado na própria Constituição Federal em resposta às violações cometidas durante o período militar, bem como está presente na Lei de Diretrizes e Bases da Educação Nacional e demais documentos oficiais do Governo Federal, como a Lei no 10.172/2001 que refere-se ao Plano Nacional de Educação (PNE), a Portaria no 66/2003 que cria o Plano Nacional de Educação em Direitos Humanos (PNEDH) e a Resolução CNE $n^{\circ} 1$ de 2012, que estabelece Diretrizes Nacionais para a Educação em Direitos Humanos, entre outros.

Tais políticas incorporam elementos de diversos instrumentos internacionais de direitos humanos, dos quais o Estado brasileiro é signatário, configurando-se como políticas educacionais direcionadas para a formação de sujeitos de direitos. No que diz respeito ao PNEDH, este define a Educação em Direitos Humanos como um processo multidimensional e sistemático, orientado para a formação de sujeitos de direitos, articulando os seguintes princípios:

a) apreensão de conhecimentos historicamente construídos sobre direitos humanos e a sua relação com os contextos internacional, nacional e local; b) afirmação de valores, atitudes e práticas sociais que expressem a cultura dos direitos humanos em todos os espaços da sociedade; c) formação de uma consciência cidadã capaz de se fazer presente em níveis cognitivo, social, ético e político; d) desenvolvimento de processos metodológicos participativos e de construção coletiva, utilizando linguagens e materiais didáticos contextualizados; e) fortalecimento de práticas individuais e sociais que gerem ações e instrumentos em favor da promoção, da proteção e da defesa dos direitos humanos, bem como da reparação das violações (BRASIL, 2007, p. 25)

No que concerne às Diretrizes Nacionais para a EDH, esta prática é compreendida como um eixo fundamental do direito à 
educação, referindo-se à aplicação de concepções e práticas educativas constituídas com base nos direitos humanos e em seus sistemas de proteção, promoção, defesa e aplicação na vida cotidiana dos sujeitos de direitos. Desse modo, fundamenta-se nos princípios da dignidade humana, reconhecimento e valorização das diferenças, igualdade de direitos e laicidade do Estado, dentre outros (BRASIL, 2012).

À vista disso, considerando que as Instituições de Ensino Superior são detentoras de um lugar privilegiado, concebemos a Educação em Direitos Humanos como um dos compromissos sociais da universidade, uma vez que pode contribuir para a produção e disseminação de conhecimentos para o desenvolvimento humano através da incorporação dos princípios básicos dos direitos humanos em projetos de ensino, pesquisa e extensão.

\section{AEDUCAÇÃOEMDIREITOSHUMANOSEOCOMPROMISSOSOCIALDAUNIVERSIDADE}

Neste tópico, abordaremos como a Educação em Direitos Humanos manifestar-se-ia, de forma geral, no ensino superior e, especificamente, na universidade pública. Através desta elucidação, espera-se compreender de que forma a EDH universitária poderia contribuir à realização do compromisso social destas instituições. Argumentamos, nesse sentido, que a EDH poderia ser enquadrada em uma perspectiva mais ampla que impele às universidades públicas brasileiras a comprometer-se com assuntos relativos à cidadania, à democratização do conhecimento e da sociedade, e a uma formação, pesquisa e extensão conectadas aos problemas sociais e às populações que possuem seus direitos violados cotidianamente.

Porém, antes de explorarmos este debate em particular, convém reconhecer a universidade enquanto uma instituição social, o que implica, como aponta Chauí (2003) e Bernheim \& Chauí (2008), que estas expressam de determinadas maneiras a estrutura e a modo de funcionamento da sociedade: "tanto é assim que, dentro da universidade como instituição, encontramos opiniões, projetos e atitudes conflitantes, que refletem as divisões e contradições da sociedade como um todo" (BERNHEIM; CHAUÍ, 2008, p. 18). Porém, esta relação simbiótica entre o interno e o externo não ocorreria sem um filtro característico das universidades: a autonomia. Isso quer dizer, ainda retomando Chauí (2003), que estas instituições sociais podem assimilar de forma crítica as demandas e influências externas, pois são uma "prática social" legitimada e reconhecida em âmbito público com um princípio de diferenciação. Assim, pode-se dizer que: 
Uma universidade enclausurada expressa o modo como determinada sociedade concebe o saber; uma universidade militante expressa o modo como uma parte de determinada sociedade pretende que o saber esteja a serviço de determinadas políticas. Da mesma forma, uma universidade funcional e operacional, que forma mão-de-obra especializada para o mercado de trabalho, espelha uma sociedade que considera o mercado como a ratio última da vida social. Por outro lado, uma universidade que considera o saber pelo prisma do direito do cidadão, faz o que pode para refrear a despersonalização e valoriza a democratização, reflete uma sociedade em que os valores democráticos da cidadania são imperativo ético e político da vida universitária (BERNHEIM; CHAUÍ, 2008, p. 18)

Vale a pena pontuar, nesse aspecto, a perspectiva de Sguissardi (2015) que, retomado Ristoff (2014), argumenta que não seria verdade a tese de que o campus é um puro reflexo de seu contexto pois, sobretudo no Brasil e na América Latina em geral, as universidades muitas vezes distorcem a imagem da sociedade aguçando suas contradições. Essa afirmação é apoiada pelas seguintes constatações em relação ao panorama do ensino superior no Brasil (SGUISSARDI, 2015): há um processo de massificação - e não de democratização - privada do Ensino Superior e de mercantilização da universidade pública que acarreta em uma expansão "que a mantém como de elite e de alta qualificação para poucos, enquanto adquire traços de "sistema" de massas e de baixa qualificação para muitos. Isto poria em dúvida o alcance das pretendidas metas oficiais de sua democratização" (p. 869); e, corroborando com isso, Dagnino (2015) e Segrera (2016) apontam que as universidades, tidas como instituições de maior qualidade, são elitizadas em sua composição estudantil e professoral, enquanto que a população mais pobre acessa faculdades privadas que se abstêm da pesquisa, da extensão e da formação crítica. ${ }^{2}$

Não é nossa intenção entrar neste debate. Com ele, gostaríamos de pontuar que a universidade é uma instituição social complexa onde se apresentam uma série de demandas, desafios, contradições e debates. Além do mais, os dois pontos de vista não precisam ser tomados em contradição, visto que se admite a possibilidade de a universidade negar e excluir certas demandas, transformando sua autonomia em heteronomia e, além do mais, os processos de elitização e massificação também expressam determinadas condições históricas de dominação e poder da própria sociedade (CHAUÍ, 2003; CHAUÍ, 2001). ${ }^{3}$ De qualquer forma, os autores concordam com um ponto: sendo a universidade uma instituição social, deve-se trabalhar na perspectiva de que há a necessidade de democratizá-la - tanto no que se refere ao acesso das classes mais pobres quanto a própria democratização do conhecimento em si - e de direcioná-la à defesa da cidadania e de uma pesquisa e formação críticas e reflexivas. 
Para citar alguns exemplos, e para contextualizar o debate contemporâneo acerca do compromisso social no âmbito da formação, da pesquisa e da extensão, discute-se atualmente em que medida o ensino e a produção de conhecimento deveriam obedecer aos imperativos mercadológicos de um mundo laboral mais instável e flexível (mais desigual e exclusivo, por sinal) em que o conhecimento torna-se cada vez mais um fator produtivo que determina o crescimento e a competitividade de empresas e nações através de inovações tecnológicas - a chamada economia do conhecimento (DIAS SOBRINHO, 2013; 2014; GORGEN, 2014); ou se o ensino, a ciência e a extensão deveriam preparar indivíduos e produzir conhecimento, ainda que aptos a exercer suas funções produtivas, para atuar crítica e reflexivamente diante de problemas sociais diversos e variados que atingem nossa sociedade, sobretudo para com segmentos e classes sociais marginalizadas e exploradas (DIAS SOBRINHO, 2015; DAGNINO, 2015). ${ }^{4}$

Neste ponto, cabe um adendo: ainda que a dualidade estabelecida entre uma ou alternativa seja um debate controverso, vale destacar que muitos autores atribuem à aproximação cada vez mais simbiótica entre a universidade e os interesses do mercado, inclusive emulando o modus operandi administrativo, avaliativo e de controle do setor produtivo - processos chamados de privatização e mercantilização do ensino superior e da universidade pública - como uma das causas pelas quais as universidades brasileiras (e em âmbito latino-americano, em geral) vêm perdendo sua capacidade de formar cidadãos e intelectuais comprometidos com as mazelas sociais mais concretas das sociedades periféricas (GOERGEN, 2014; CHAUÍ, 2003; SERAFIM, 2011, MARTINS, 2008; DIAS SOBRINHO, 2013; 2014; 2015; ALVA, 2014)..$^{5}$ Nesse ponto, achamos pertinente ressaltar que este debate percorre a própria trajetória do Ensino Superior bem como política científica e tecnológica - brasileira, sobretudo a partir da redemocratização ocorrida no final da década de 1980, quando as discussões acerca da cidadania e da democracia se chocam com o avanço do neoliberalismo no país. Mais que isso, estes conflitos acentuam-se, atualmente, por conta do fortalecimento das tendências à mercantilização e privatização do ensino superior e da universidade pública, prejudicando os esforços em direção a uma formação crítica e uma pesquisa mais direcionada aos problemas sociais da população (COSTA, 2018; ANDES, 2018, LEHER et al., 2017). Apesar da edição do Pacto Universitário pela Promoção do Respeito à Diversidade, da Cultura da Paz e dos Direitos Humanos, concretizado em 2016 pelo 
Ministério da Educação (MEC), o qual comentaremos mais a frente, a conjuntura econômica e política que se apresenta à universidade pública revela a acentuação dos problemas de financiamento e sucateamento, derivados em alguma medida da condução da política de corte e congelamento de gastos públicos perpetuada em âmbito federal, abrindo caminho ao fortalecimento das discussões sobre a privatização e mercantilização deste nível de ensino (FIGUEIREDO, 2017; ANDES, 2018, LEHER et al., 2017).

Como vínhamos argumentando, a Educação em Direitos Humanos alinha-se mais a esta última perspectiva - a da consideração da construção do saber e da formação pelo prisma do direito do cidadão e da democratização, pois tanto os documentos legais aprovados em âmbito nacional quanto os autores considerados neste estudo tomam esta perspectiva, de forma direta ou indireta, como pano de fundo. Com efeito, o próprio Plano Nacional de Educação em Direitos Humanos pontua que:

A partir desses marcos legais [Constituição Federal de 1988 e Lei de Diretrizes e Bases da Educação], as universidades brasileiras, especialmente as públicas, em seu papel de instituições sociais irradiadoras de conhecimentos e práticas novas, assumiram o compromisso com a formação crítica, a criação de um pensamento autônomo, a descoberta do novo e a mudança histórica (...) Tal dimensão torna-se ainda mais necessária se considerarmos o atual contexto de desigualdade e exclusão social, mudanças ambientais e agravamento da violência, que coloca em risco permanente a vigência dos direitos humanos. As instituições de ensino superior precisam responder a esse cenário, contribuindo não só com a sua capacidade crítica, mas também com uma postura democratizante e emancipadora que sirva de parâmetro para toda a sociedade (BRASIL, 2007, p. 37-38)

Chama a atenção o reconhecimento explícito de que a universidade é uma instituição social regida pelos princípios da indissociabilidade entre ensino, pesquisa e extensão, assumindo, dessa forma, "o compromisso com a formação crítica, a criação de um pensamento autônomo, a descoberta do novo e a mudança histórica" (BRASIL, 2007, p. 37). Para tanto, torna-se necessário considerar alguns princípios para a incorporação da EDH nas universidades considerando-se estes três pilares:

a) a universidade, como criadora e disseminadora de conhecimento, é instituição social com vocação republicana, diferenciada e autônoma, comprometida com a democracia e a cidadania; b) os preceitos da igualdade, da liberdade e da justiça devem guiar as ações universitárias, de modo a garantir a democratização da informação, o acesso por parte de grupos sociais vulneráveis ou excluídos e o compromisso cívico-ético com a implementação de políticas públicas voltadas para as necessidades básicas desses segmentos; c) o princípio básico norteador da 
educação em direitos humanos como prática permanente, contínua e global, deve estar voltado para a transformação da sociedade, com vistas à difusão de valores democráticos e republicanos, ao fortalecimento da esfera pública e à construção de projetos coletivos; d) a educação em direitos humanos deve se constituir em princípio ético-político orientador da formulação e crítica da prática das instituições de ensino superior; e) as atividades acadêmicas devem se voltar para a formação de uma cultura baseada na universalidade, indivisibilidade e interdependência dos direitos humanos, como tema transversal e transdisciplinar, de modo a inspirar a elaboração de programas específicos e metodologias adequadas nos cursos de graduação e pós-graduação, entre outros; f) a construção da indissociabilidade entre ensino, pesquisa e extensão deve ser feita articulando as diferentes áreas do conhecimento, os setores de pesquisa e extensão, os programas de graduação, de pós-graduação e outros; g) o compromisso com a construção de uma cultura de respeito aos direitos humanos na relação com os movimentos e entidades sociais, além de grupos em situação de exclusão ou discriminação; h) a participação das IES na formação de agentes sociais de educação em direitos humanos e na avaliação do processo de implementação do PNEDH (BRASIL, 2007, p. 38-39)

Desse modo, paralelamente ao PNEDH, as Diretrizes Nacionais para a Educação em Direitos Humanos expõem que as IES devem incorporar a EDH de modo transversal nos Programas Pedagógicos dos Cursos (PPCs), bem como nos projetos de pesquisa e extensão (BRASIL, 2012). No que diz respeito à incorporação da perspectiva da EDH nos PPCs, esta poderá ocorrer por meio de diferentes formas:

i. pela transversalidade, por meio de temas relacionados aos Direitos Humanos e tratados interdisciplinarmente; ii. como um conteúdo específico de uma das disciplinas já existentes no currículo escolar; iii. de maneira mista, ou seja, combinando transversalidade e disciplinaridade (BRASIL, 2012, p. 12)

Nesta esfera, destaca-se também a Lei de Diretrizes e Bases (LDB), bem como os Parâmetros Curriculares Nacionais (PCNs) e as orientações para a criação dos Projetos Político Pedagógicos (PPP), os quais incorporam a perspectiva do compromisso da universidade para com uma formação profissional e uma formação para a cidadania. Desse modo, nenhum curso pode deixar de integrar esta perspectiva no seu currículo, devendo ser superadas as resistências internas e discordâncias por parte do corpo docente das universidades (TOSI, 2005). Para Lourenço e Afonso (2015), é necessário a criação de uma disciplina interdisciplinar optativa em direitos humanos, devendo ser ofertada para todos os cursos durante todos os períodos. Esta, por sua vez, deve ser construída coletivamente e ser composta por estudantes de diferentes cursos, de forma a contribuir para com a vivência dos estudantes, integrando práticas sociais e aproximandoos à área de conhecimento dos direitos humanos. 
$\mathrm{Na}$ modalidade da pesquisa, esfera onde a universidade pode contribuir de forma mais específica visto que é a instituição que, muitas vezes, encabeça a produção intelectual de uma sociedade, a EDH deve ser incorporada através de políticas de incentivo à realização de estudos e investigações especializadas, criando núcleos de estudos e pesquisas com atuação nos seguintes princípios: dignidade humana; igualdade de direitos; reconhecimento e valorização das diferenças e das diversidades; laicidade do Estado; democracia na educação; transversalidade, vivência e globalidade; e sustentabilidade socioambiental (BRASIL, 2012). Dessa forma, a partir de um diálogo interdisciplinar, a universidade seria capaz de estimular e fomentar a produção científica na área dos direitos humanos (TOSI, 2005; CARDOSO, 2016; PIOVESAN, 2005), bem como contribuir para o desenvolvimento da cultura de direitos humanos, fortalecendo a luta contra as violações de direitos e o reconhecimento de comunidades e grupos socialmente excluídos (LOURENÇO; AFONSO, 2015).

No âmbito da extensão, porta de entrada da temática dos direitos humanos na universidade, deve-se ir muito além do que uma prestação de serviço à comunidade, de forma a assumir um caráter educativo amplo, contribuindo com ações voltadas para os segmentos sociais "subalternos", gerando "uma cultura pela paz e a democracia [...] capaz de sustentar a construção de um Estado democrático de direito" (TOSI, 2005, p. 29). Destaca-se que tanto o Plano Nacional de Extensão Universitária, quanto as DNEDH, reforçam o debate acerca do compromisso social da universidade para com os direitos humanos, demonstrando uma "necessidade das IES atenderem demandas não só formativas, mas também de intervenção por meio da aproximação com os segmentos sociais em situação de exclusão social e violação de direitos, assim como os movimentos sociais e a gestão pública” (BRASIL, 2012, p. 16). Faz-se necessário, neste sentido, a constituição de núcleos interdisciplinares e observatórios de $\mathrm{EDH}$, de forma a propor intervenções sociais apoiadas nas atividades de ensino e pesquisa e promovendo o fortalecimento da cidadania junto à sociedade civil (LOURENÇO; AFONSO, 2015).

Destaca-se, na literatura que trata sobre EDH, a necessidade de construí-la de forma trans e interdisciplinar, bem como de forma indissociável no que se refere ao ensino, à pesquisa e à extensão. De fato, retomando Bernheim (2007), a trans, multi e a interdisciplinaridade constituem-se como desafios importantes às universidades Latino Americanas de forma geral - em âmbito global também, inclusive; já para Dagnino (2015), partindo de outra perspectiva, a produção 
de conhecimento deve ser orientada por problemas concretos e de pertinência social, o que exige a consideração de se integrar as diferentes disciplinas em torno destes. Além disso, pode-se atentar especialmente ao conteúdo do debate sobre EDH na universidade: a preocupação para com assuntos e temáticas referentes a problemas sociais crônicos de nossa sociedade, contextualizados localmente, mas visualizados em sua totalidade e universalidade. Nesse ponto, corrobora-se com Dagnino (2015) e com Dagnino \& Dias (2007) a uma mudança na agenda de pesquisa que consiga incorporar debates de maior pertinência social em detrimento aos temas internacionalmente decididos pelas comunidades de pesquisa dominantes - sem, entretanto, que o conhecimento construído se desconecte de uma agenda global, mas a assuma de forma crítica (BERNHEIM, 2007).

Sobre a extensão, visualiza-se uma intersecção interessante entre a EDH e o debate atual sobre a extensão universitária. Se adotarmos as recomendações do Fórum de Pró-Reitores de Extensão das Universidades Públicas Brasileiras (FORPROEX), principal ator extensionista nacional desde a redemocratização do país em 1988 sobre a extensão, veremos que os Direitos Humanos são abordados, indireta ou diretamente, enquanto uma das temáticas principais dos objetivos extensionistas dos quais as universidades deveriam perseguir. Antes de passarmos a mostrar a interligação da extensão com os DH, pode-se explicar o conceito extensionista da entidade. Assim, a extensão foi entendida como (FORPROEX, 1987): um processo educativo, cultural e científico, articulador do ensino e da pesquisa e viabilizador da relação transformadora entre universidade e sociedade; a extensão seria uma "via de mão" dupla, ao encontrar na sociedade a oportunidade de elaborar uma práxis acadêmica que transformasse, além da sociedade, a própria academia; e, assim, a produção de conhecimento resultaria do confronto com a realidade social brasileira e regional, tendo a extensão como instrumentalizadora de um trabalho interdisciplinar e dialógico.

No Plano Nacional de Extensão (1999), construído pelo Forproex, afirmaram-se enquanto objetivos do documento: assegurar relações bidirecionais entre a universidade e a sociedade de forma a atender os problemas sociais mais urgentes tais como saúde, educação, habitação e preservação do meio ambiente; inserir a universidade na participação de políticas públicas voltadas à maioria da população. Mais tarde, em 2013, editou-se a Política Nacional de Extensão, que acabou por incluir diretamente o termo dentre os objetivos extensionistas: 
9. priorizar práticas voltadas para o atendimento de necessidades sociais (por exemplo, habitação, produção de alimentos, geração de emprego, redistribuição da renda), relacionadas com as áreas de Comunicação, Cultura, Direitos Humanos e Justiça, Educação, Meio Ambiente, Saúde, Tecnologia e Produção, Trabalho (FORPROEX, 2013, p. 5)

Além do mais, a definição de Extensão adotada pelo Forproex, qual seja, a de um processo educativo, cultural e científico que articula o ensino e a pesquisa viabilizando, assim, a relação transformadora entre universidade e sociedade (FORPROEX, 2013). Com efeito, muito do que se discute sobre EDH é considerado nesta definição: a necessidade da indissociabilidade, como já comentado; a necessidade de se estabelecer contato - sobretudo com segmentos sociais mais vulneráveis e excluídos - e a necessidade de se estabelecer relações dialógicas para com eles.

Desse modo, tendo em vista que a universidade é detentora de um espaço privilegiado, assume-se que esta possui um compromisso relevante a cumprir no âmbito do "Sistema Nacional de Direitos Humanos", seja através da transmissão do saber, da produção do saber, bem como da intervenção social. "Há que se resgatar o potencial ético e transformador das universidades, na construção de uma cultura de direitos humanos [...], já que os direitos humanos refletem a única plataforma emancipatória de nosso tempo" (PIOVESAN, 2005, p. 81).

Em suma, visualiza-se a EDH no ensino superior como uma prática a contribuir para a construção da cidadania e para a democratização da universidade e do conhecimento através da indissociabilidade entre as funções universitárias, da transversalidade das ações de DH no âmbito acadêmico, bem como da construção interdisciplinar do conhecimento. É claro que, considerando-se o que foi dito, a EDH ainda possui diversas dificuldades de expansão e concretização, e muito da agenda temática que trouxemos à tona se apresenta enquanto projeção normativa - dado que sua evolução conceitual e prática ainda está em desenvolvimento.

\section{ENTRAVESEDESAFIOSDA EDUCAÇÃOEMDIREITOS HUMANOSNA UNIVERSIDADE PÚBLICA}

O debate realizado anteriormente buscou articular de que forma, através da Educação em Direitos Humanos, a universidade realizaria seu compromisso social. Nesta perspectiva, apresentaremos um panorama de alguns desafios e tensões na incorporação da EDH no ensino superior, especialmente neste contexto marcado pelo fortalecimento do processo de mercantilização da universidade pública. Alguns desses empecilhos são apontados por Candau e Sacavino (2008). 
O primeiro deles consiste na desconstrução da visão do senso comum acerca dos direitos humanos. Este desafio relaciona-se à visão deturpada de que os direitos humanos consistem nos "direitos à proteção dos bandidos", bem como está associada à ideia de que estes abrangem apenas os direitos relativos à liberdade. Em vista disso, tal desconstrução deve assumir a perspectiva de que a ideia central dos direitos humanos diz respeito à proteção da dignidade da pessoa humana, a defesa do estado de direito, associando-se à defesa da democracia e desenvolvimento de uma cultura pautada nos direitos humanos para todos, sem distinção de raça, religião, classe social e demais "categorizações" que podem gerar algum tipo de preconceito ou não-aceitação.

O segundo desafio apresentado pelas autoras Candau e Sacavino (2008) diz respeito a assumir uma concepção de educação em direitos humanos e explicitar o que se pretende atingir em cada situação concreta. O horizonte de sentido da Educação em Direitos Humanos deve ser compreendido a partir da formação de sujeitos de direitos, empoderamento de atores sociais e o resgate da memória histórica dos direitos humanos, contornando a visão polissêmica que perpassa sobre este debate.

A articulação de ações de sensibilização e de formação consiste no terceiro desafio a ser superado. Este, por sua vez, referese à associação de ações de curta duração com os programas de formação destinados a possíveis multiplicadores, de forma a investir de modo mais intenso nestes programas, difundindo o PNEDH, bem como permitindo que a afirmação dos direitos humanos penetre nos diferentes âmbitos da sociedade. Como exemplo a ser analisado, podemos citar o "Pacto Universitário pela Promoção do Respeito à Diversidade, da Cultura da Paz e dos Direitos Humanos", o qual emerge em novembro de 2016 através de uma iniciativa da Secretaria Especial de Direitos Humanos do Ministério da Justiça em parceria com o Ministério da Educação, se constituindo enquanto mais um documento base da Educação em Direitos Humanos, especialmente no que se refere à Educação Superior. O Pacto ${ }^{6}$ tem como objetivo fomentar a elaboração, implementação, monitoramento e disseminação de atividades e projetos que se direcionam à promoção e defesa dos direitos humanos fundamentais, como forma de fortalecer a prática da EDH nas Instituições de Ensino Superior nas esferas do ensino, pesquisa, extensão, gestão e convivência universitária e comunitária (BRASIL, 2016; PIOVESAN, 2017).

Em vista disso, assinala em seu acordo de cooperação, 
a responsabilidade das Instituições de Ensino Superior com a formação comprometida com a construção da paz, da defesa dos Direitos Humanos e dos valores da democracia, além da responsabilidade de gerar conhecimento visando a atender os desafios dos Direitos Humanos, como a erradicação da pobreza, do preconceito, da discriminação e da superação da violência na sociedade e no âmbito universitário (BRASIL, 2016, p. 2).

Assim, baseia-se na possibilidade, bem como necessidade de incorporação da EDH no ensino superior, dada através da aproximação entre as instituições acadêmicas junto à comunidade, a inclusão de conhecimentos teóricos e práticos relativos aos princípios dos direitos humanos nas esferas institucionais e no processo educativo; cabendo ao representante da universidade a adesão voluntária a este instrumento. Dentre suas principais diretivas, estão a realização de campanhas de sensibilização do corpo docente, discente e funcionários; a formação de canais institucionais capacitados para o recebimento, levantamento e apuração de denúncias relativas a violações de direitos; a incorporação da $\mathrm{EDH}$ nos projetos político-pedagógicos dessas Instituições; a implementação de ações no âmbito do reconhecimento e valorização de práticas de promoção e defesa dos direitos humanos; e, "estabelecimento de mecanismos institucionais dentro de cada universidade para coordenar, fomentar e monitorar o cumprimento das medidas adotadas mediante a criação de Comitês Gestores e de um Comitê Nacional" (PIOVESAN, 2017, p. 32). Cabe ainda destacar o edital no 38/2017, lançado em agosto deste mesmo ano, por meio de uma parceria entre a Fundação Capes e a Secretaria de Educação Continuada, Alfabetização, Diversidade e Inclusão (SECADI), do Ministério da Educação. O edital tinha como objetivo estimular e fomentar projetos dedicados à temática da "Educação em Direitos Humanos e Diversidades" no âmbito das Instituições de Ensino Superior, contemplando diferentes modalidades de apoio, como bolsas de iniciação científica, mestrado e pós-doutorado (BRASIL, 2017).

Torna-se necessário construir ambientes educativos que respeitem e promovam os direitos humanos, isto é, a EDH não deve ser reduzida à inserção de alguns conteúdos no âmbito educativo, mas sim deve ser incorporada em todas as relações, bem como no currículo acadêmico como um dos eixos norteadores dos Programas Pedagógicos. A introdução da EDH deve ser realizada desde a formação inicial dos educadores, de forma continuada, articulando políticas de igualdade e de reconhecimento das diferenças, bem como estimulando a criação de materiais de apoio que permitam favorecer o diálogo intercultural e o reconhecimento de diferentes grupos sociais 
étnicos e culturais (CANDAU; SACAVINO, 2008), assim como já é previsto pela resolução $\mathrm{CNE} / \mathrm{CP} \mathrm{n}^{\circ} 2$, de $1^{\circ}$ de julho de 2015 , que prevê a incorporação da EDH enquanto um conteúdo necessário à formação de professores da educação básica (BRASIL, 2015).

Segundo Salvioli (2009), odesafio predominante na incorporação da EDH no Ensino Superior consiste em driblar a capacitação docente para o ensinamento dos direitos humanos, isto é, deve-se estimular e formar o corpo docente para que este cumpra esse papel educativo, sendo um importante ator para o desenvolvimento da EDH no Brasil, bem como contribuindo para a transmissão do conteúdo e dos mecanismos e instrumentos de defesa, proteção e promoção dos direitos humanos. Desse modo, para além dos desafios apresentados nesta seção, fora possível desenvolver hipóteses que atravancam a incorporação da Educação em Direitos Humanos no Ensino Superior, mais especificamente no que diz respeito à universidade pública.

Além destes debates apresentados pela literatura especializada no tema da EDH, as leituras acerca do compromisso social da universidade fizeram com que elaborássemos algumas hipóteses que representam outros empecilhos, de cunho mais amplo, à efetivação e expansão da EDH no ensino superior e nas universidades. Assim, identificou-se algumas situações que obstaculizariam a efetivação da EDH, lançadas aqui como ideias hipotéticas: i. a dificuldade de se incorporar a EDH para além dos cursos de Direito, visto que a bibliografia consultada aponta a necessidade da transversalidade da temática diante dos currículos e das pesquisas de praticamente todas as áreas do conhecimento; ii. a debilidade relativa da extensão enquanto função universitária, incluindo-se à dificuldade em se praticar a indissociabilidade e a inter, trans e multidisciplinaridade requisitos exigidos para qualificar a prática da $\mathrm{EDH}$ na universidade; iii. os processos de privatização do ensino superior e mercantilização da universidade pública, que ofereceriam entraves a uma formação e pesquisa críticas e comprometidas com as classes sociais excluídas; e, conectados a isto, as próprias iv. dificuldades em se democratizar o acesso à universidade: do que adianta efetivar a EDH se, objetivamente, a universidade continua elitizada e excludente.

No que diz respeito ao desafio relativo à incorporação da perspectiva da Educação em Direitos Humanos para além dos cursos de Direito, do ponto de vista da transversalidade e da interdisciplinaridade, entende-se que há uma complexidade arrolada à dimensão política dos Projetos Pedagógicos dos Cursos universitários, uma vez que a ênfase dada à temática dos direitos humanos, encontra-se, em uma perspectiva geral, 
mais centrada nos cursos da área do Direito. Através deste panorama, assume-se que tais projetos devem manifestar um compromisso social da educação, de forma a superar a visão da disciplinaridade, bem como refrear-se a seguir os interesses do mercado (CARDOSO, 2016). Desse modo, faz-se necessário que estes incorporem o compromisso éticopolítico na formação em todos os cursos universitários, abordando a temática dos direitos humanos por meio da transversalidade entre ensino, pesquisa e extensão, bem como assumindo uma perspectiva interdisciplinar perante a interface da formação universitária.

O segundo entrave que identificamos diz respeito à debilidade relativa da função extensão universitária nas universidades brasileiras (DAGNINO, 2015). Especialmente, podemos nos referir à extensão comunitária, responsável pelo contato entre a universidade e segmentos sociais excluídos, marginalizados ou em situação de vulnerabilidade social. Gostaríamos de argumentar, também, que à falta de compreensão, confusão e nebulosidade que o tema extensão possui na comunidade acadêmica, reflexo da própria trajetória extensionista brasileira, marcada por práticas e concepções distintas, geralmente assistemáticas e fragmentadas, tais como cursos de extensão, prestação de serviços, atividades culturais, dentre outros (PAULA, 2013; FRAGA, 2012; SOUZA, 2010).

Nesse aspecto, EDH nas universidades seria prejudicada à medida da própria condição da função extensão, especialmente à comunitária, na maioria das universidades públicas brasileiras, pois, como argumentamos, a extensão seria a porta de entrada à EDH nas universidades, uma vez que articularia o ensino e a pesquisa de forma interdisciplinar e, além do mais, realizaria contato efetivo com as comunidades externas à academia. Assim, conforme Silva (2012) e Freire (2008), a extensão, a depender da perspectiva adotada, contribuiria ao auxílio concreto à efetivação dos direitos humanos no Brasil, sobretudo no que se refere à participação das universidades neste processo.

O terceiro entrave, assim como a Extensão, é um fenômeno mais amplo que infringe mudanças em diversos aspectos do Ensino Superior e das universidades. Observa-se, como já apontamos na seção anterior, que a educação em nível superior passa por processos de mercantilização e privatização - ou expansão da privatização - das universidades públicas e do ensino superior brasileiro em geral (MARTINS, 2008; LEHER, 2004; ROSA, 2016). Ambos os processos, apesar de pavimentados anteriormente, sobretudo pelos governos militares, ganham força diante da enxurrada neoliberal que atingiu o país a partir das décadas de 1980 e $1990 .^{7}$ Assim, no limiar 
dos anos 2000, pode-se apontar alguns fatos que os caracterizam, como a redução ou estagnação do financiamento público à educação em geral, o surgimento de novos modelos empresariais provedores de educação em busca de lucro, a adoção nas universidades de mecanismos de administração semelhantes aos empresariais, dentre outros (CAMARGO et al., 2003). Além do mais, observa-se:

\footnotetext{
1) que era preciso redefinir a função do governo (Estado) com relação ao ensino superior, reduzindo sua participação enquanto organizador e financiador, e, consequentemente, aumentando sua dimensão avaliadora do ensino e das IES (...) 2) fomentar a diversificação das IES e a diferenciação das modalidades de ensino, desestimulando o "modelo único" e criando condições de acesso mais variadas, para públicos também variados; 3) incentivar as IES públicas a diversificarem suas fontes de financiamento por meio de parcerias (sobretudo com o setor privado) e com a adoção de estratégias de financiamento mais afetas à lógica do mercado; 4) vincular o financiamento público às IES públicas a uma política de resultados, relacionadas com metas de eficiência, de eficácia, sendo estas entendidas como um novo sentido para a qualidade e para as práticas de avaliação. No caso do financiamento à pesquisa científica e tecnológica, ter a "inovação" como centro dinâmico dessa cobrança de resultados e da orientação das políticas; 5) favorecer e estimular, no conjunto da educação superior, o funcionamento do mercado como ente regulador (...) e 6) promover "alternativas" de ensino mais baratas para fazer frente ao problema da escassez de recursos e do baixo índice de acesso da população jovem ao nível superior (MINTO, 2011, p. 239 - 240)
}

Simbolicamente, pode-se dizer que a mercantilização da universidade pública ocorre quando a educação deixa de ser considerada socialmente - ou internamente às instituições - enquanto um direito e um bem público para tornar-se mercadoria (DIAS SOBRINHO, 2013). Ou, como aponta Chauí (2003), quando a universidade deixa de ser uma instituição social, pautada pelo compromisso com a cidadania, democracia e pela autonomia, para transformar-se uma universidade operacional.

Retomando Alva (2014), permitir que a educação seja modelada pelo mundo e valores empresariais dificultaria a concretização de diversos valores voltados ao ser humano em sua integralidade enquanto cidadão e sujeito de direitos. Moldar currículos pedagógicos ao entendimento de conselhos de classe e de visão utilitarista e imediata de uma formação que o atual mercado deseja é impedir que novos conhecimentos sejam descobertos. É nesse ponto que estabelecemos uma dualidade importante: a mercantilização empecilha a capacidade de formar cidadãos críticos e conhecimentos comprometidos com os problemas sociais mais concretos e os segmentos marginalizados, excluídos e historicamente oprimidos. 
Não se trata, porém, de excluir a formação profissional e a necessidade de produzir conhecimentos que apoiem processos de desenvolvimento econômico, mas de lançar a hipótese de que os processos de mercantilização e privatização da universidade pública podem inibir a Educação em Direitos Humanos nos seguintes termos: a EDH exige formação crítica e reflexiva em relação aos problemas humanos e sociais que escapam da ordem da produção ou que tem origem nestas mesmas relações produtivas; a EDH exige que se preserve a universidade enquanto um ambiente de produção de conhecimento plural e diversificado, com enraizamento nos problemas locais e, ao mesmo tempo, pretensão à universalidade (assim como os Direitos Humanos apregoam); e, dessa forma, demanda tempo, debates democráticos e inclusivos, bem como uma extensão comunitária fortalecida; dificilmente a EDH captaria recursos externos e, tanto na pesquisa e na extensão, prescinde de recursos públicos; além do mais, a EDH parte do pressuposto de que a educação é um direito que, a nosso ver, deveria manter-se público e direcionar-se à democratização do acesso à universidade e não à massificação estratificada e segmentada e excludente.

Com efeito, para Dalbosco (2015), a formação técnica especializada deve ser mesclada, nas universidades, a uma formação cultural e humanista, que consigam transcender aos interesses do mercado de trabalho e das empresas e conectar-se com problemas tais quais meio ambiente, pobreza, exclusão das minorias, dentre outros. Isso porque, na perspectiva do autor, o exercício da cidadania democrática pressupõe a inclusão de conceitos de formação cultural "que precisam estar presentes em qualquer currículo escolar ou universitário voltado à educação de novas gerações, a saber, o pensamento crítico, a cidadania universal e a capacidade imaginativa" (DALBOSCO, 2015, p.124).

Já Dias Sobrinho $(2013 ; 2015)$ argumenta à defesa de uma universidade comprometida com a construção da cidadania e que defenda os direitos humanos mediante a consideração da educação enquanto um bem público e comum. Nas palavras do autor:

Educação é um bem público e direito social, pois tem como finalidade essencial a formação de sujeitos e, por consequência, o aprofundamento da cidadania e da democratização da sociedade. O conceito de bem público é aqui entendido como um princípio, isto é, como um imperativo moral que sobrepõe a dignidade humana aos interesses, inclinações e circunstâncias individuais (...) A ideia, ou ideal, de edificação da humanidade como escopo da educação não se coaduna com a lógica da mercantilização da vida humana, em geral, nem da mercadorização da 
educação, em particular. É preciso refletir um pouco mais sobre esse tema, pois os sistemas de educação superior estão se tornando cada vez mais privatizados, e isso poderia produzir uma crescente mercadorização da formação e dos conhecimentos (DIAS SOBRINHO, 2013, p. 109-110)

No que se refere à produção e circulação do conhecimento, vale a mesma ideia:

\footnotetext{
Nessa linha de raciocínio, o conhecimento tem valor público e social. Pertence à esfera dos direitos humanos e dos projetos civilizacionais. O conhecimento é conteúdo integrante da formação humana social, ética, política, moral e estética (...) Contudo, nem todo conhecimento que hoje se produz e se reproduz na universidade contribui para tornar mais ético e justo o viver humano. Ao contrário. Fazendo parte da tendência geral de mercadorização da sociedade que grassa por toda parte, o conhecimento está sendo produzido e irradiado mais pelo critério de valor utilitário que pelo significado humano formativo (DIAS SOBRINHO, 2015, p. 585-587)
}

$\mathrm{Na}$ esteira deste debate, temos o quarto empecilho à concretização da EDH nas universidades: as dificuldades em se democratizar o acesso à universidade. Não vamos, claro, perpassar pela história do ensino superior brasileiro para demonstrar as causas desta dificuldade, mas convém constatar, como Dagnino (2015) pontua, que o acesso à educação superior de qualidade, sobretudo à universidade pública que realiza pesquisa, ensino e extensão, no Brasil ainda é limitado e elitizado. Além do mais, presenciou-se um aumento considerável da educação superior privada, além de um processo de oligopolização de empresas do ramo (MARQUES, 2013) - parte do fenômeno de privatização da educação superior no país.

Sobre este aspecto, Dias Sobrinho (2013) ressalta que massificar o acesso ao ensino superior não implica em democratizálo. A democratização implica, na verdade, ampliar o acesso à educação enquanto um direito, sem distinção de qualidade para os indivíduos segundo renda, classe, etnia, gênero, dentre outros. Em outras palavras, o acesso deve ser igualitário e equitativo. Sendo assim, a exclusão do acesso à educação "priva os indivíduos e, por extensão, a sociedade dos fundamentos e ferramentas cognitivos, axiológicos e práticos essenciais para a edificação de uma vida digna e construtiva" (DIAS SOBRINHO, 2013, p.116). Dessa forma, mesmo sabendo da importância de algumas políticas de expansão de universidades públicas em âmbito federal, a democratização ainda é um gargalo que atravancava a real implementação da EDH - visto que, em nossa perspectiva, é preciso inserir os grupos excluídos dos quais se quer proteger através dos $\mathrm{DH}$. 


\section{CONSIDERAÇ̃̃ES FINAIS}

Este artigo buscou debater como os temas da Educação em Direitos Humanos dialogam (ou não) com as discussões acerca do compromisso social da universidade pública. Mais do que verificar essa aproximação, a ideia foi identificar os entraves e os desafios que se impõem à concretização da $\mathrm{EDH}$, mas também ao cumprimento do papel social da universidade, nestas instituições de ensino.

A EDH, reconhecida como um direito fundamental, surge com força, a partir do final dos anos 1970 e início dos anos 1980, no processo de redemocratização ocorrido nos países latino-americanos. A EDH não se trata apenas da transferência de conhecimentos, mas está pautada em uma perspectiva de mudança cultural. Tratase de uma formação que está nucleada no respeito à dignidade humana, na formação de sujeitos de direitos, de forma a articular as perspectivas da ética, político-social e práticas concretas, no processo de empoderamento de cada ator social, especialmente àqueles que possuem menos poder nas decisões e processos coletivos; e na construção de sociedades verdadeiramente democráticas.

Buscando compreender como o ensino superior, e mais precisamente a universidade pública, se insere dentro desta temática, visualiza-se, a partir de diversos estudos e autores tanto dos Direitos Humanos quanto da educação superior pública, que as universidades públicas ainda precisam enfrentar alguns desafios para que a concretização das propostas da EDH ocorra. Conforme apontado no item anterior, os processos crescentes de mercantilização da universidade pública e de privatização do ensino superior; a fragilidade histórica da integração entre ensino, pesquisa e extensão; a dificuldade em se estabelecer um contato mais sistemático e profícuo entre a universidade e os segmentos/classes sociais mais pobres e com direitos violados; e, as dificuldades em propiciar a democratização do acesso à universidade são aspectos que freiam e/ou afastam a universidade pública das discussões da EDH, já apresentadas em legislações vigentes, mas mais que isso pressionam tal ator a se afastar sistematicamente do seu papel social. Uma universidade pública é aquela comprometida com a construção da cidadania e que defenda os direitos humanos mediante a consideração da educação enquanto um bem público e comum. Compreender e defender isto é dar conta das bases iniciais de estruturação das mudanças mais amplas que a educação em direitos humanos nos prova nos dias atuais. 


\section{REFERÊNCIAS}

ALVA, B. B. D. A educação superior em direitos humanos face à ideologia neoliberal globalizada. Revista Interdisciplinar de Direitos Humanos, n. 2, v. 2, 2, p. 115-130, 2014.

ANDES. Neoliberalismo e Política de C\&T no Brasil Um balanço crítico (1995-2016). Cadernos Andes, Brasília, n.28, p.1-144, 2018.

BENEVIDES, M. V. Educação em direitos humanos: de que se trata? Formação de Educadores. Desafios e Perspectivas. São Paulo: UNESP, 2003.

BERNHEIM, C. T. La universidad necesaria para el siglo XXI. Hispamer: Managua, 296p., 2007.

BERNHEIM, C. T.; CHAUÍ, M. Desafios da Universidade na sociedade do conhecimento. Brasília: UNESCO, 44 p., 2008.

BRASIL. Ministério da Educação. Conselho Nacional de Educação. Diretrizes Nacionais para a Educação em Direitos Humanos. Brasília, 2012.

BRASIL. Ministério da Educação. Conselho Nacional de Educação. Resolução $\mathbf{n}^{\mathbf{0}}$ 2, de

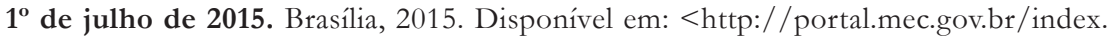
php?option $=$ com_docman\&view $=$ download\&alias $=70431-$ res - cne-cp-002-03072015pdf\&category_slug=agosto-2017-pdf\&Itemid=30192>. Acesso em: 20 ago. 2018.

BRASIL. Ministério da Educação. Fundação Capes. Programa de Educação em Direitos Humanos e Diversidades. 2017. Disponível em: <http://www.capes.gov.br/bolsas/ programas-especiais/educacao-em-direitos-humanos-diversidades>. Acesso em: 15 ago. 2018.

BRASIL. Pacto Nacional Universitário pela Promoção do Respeito à Diversidade e da Cultura da Paz e Direitos Humanos. Brasília: Ministério da Justiça, 2016. Disponível em: <http://educacaoemdireitoshumanos.mec.gov.br>. Acesso em: 15 ago. 2018.

BRASIL. Secretaria Especial dos Direitos Humanos da Presidência da República. Plano Nacional de Educação em Direitos Humanos. Brasília: SEDH/PR. 2007.

CANDAU, V. M. Educação em Direitos Humanos e estratégias metodológicas. 2008.

CANDAU, V.; SACAVINO, S. Educação em direitos humanos no Brasil: ideias-força e perspectivas de futuro. Pensamiento e ideas-fuerza de la educación en derechos humanos en Iberoamérica. Santiago, Chile: OIE/Orealc/Unesco, p. 68-83, 2008.

CARDOSO, C. M. Valores ético-políticos na formação Universitária. CARDOSO, C. M. (org.). Universidade, poder e direitos humanos. São Paulo: Cultura Acadêmica, 2016.

CHAUÍ, M. A universidade pública sob nova perspectiva. Revista Brasileira de Educação, n. 24, p. 5-15, 2003.

COSTA, C. F. A Universidade Pública e o padrão dependente de educação superior: uma análise da articulação entre as políticas de ampliação do acesso e de incentivo à inovação. Tese (doutorado) - Universidade Federal do Rio Grande do Sul, Escola de Administração, Programa de Pós-Graduação em Administração, Porto Alegre, 2018. 
DAGNINO, R. Como é a universidade de que o Brasil precisa? Avaliação, v. 20, n. 2, p. 293-333, 2015.

DAGNINO, R.; DIAS, R. A Política de C\&T Brasileira: três alternativas de explicação e orientação. Revista Brasileira de Inovação, v. 6, n. 2 jul/dez, p. 373-403, ago. 2009. ISSN 2178-2822. Disponível em: <http://ocs.ige.unicamp.br/ojs/rbi/article/view/324/243>. Acesso em: 01 fev. 2017.

DALBOSCO, A. C. Educação superior e os desafios da formação para a cidadania democrática. Avaliação, v. 20, n. 1, p. 123-142, 2015.

DIAS SOBRINHO, J. Educação superior: bem público, equidade e democratização. Avaliação, v.18, n.1, p. 107-126, 2013.

DIAS SOBRINHO, J. Universidade e novos modos de produção, circulação e aplicação do conhecimento. Avaliação, v. 19, n. 3, p. 643-662, 2014.

DIAS SOBRINHO, J. Universidade fraturada: reflexões sobre conhecimento e responsabilidade social. Avaliação, v. 20, n. 3, p. 581-601, 2015.

FIGUEIREDO, J. C. Impeachment no Brasil: O governo Temer e a privatização nas universidades públicas brasileiras. Germinal: Marxismo e Educação em Debate, v. 9, n. 3, p. 161-181, 2017.

FORPROEX. Fórum Nacional de Pró-Reitores de Extensão das Universidades Públicas Brasileiras. Plano Nacional de Extensão. 1999. Disponível em: <https://www.ufmg.br/ proex/renex/documentos/Colecao-Extensao-Universitaria/01-Plano-Nacional-Extensao/ Plano-nacional-de-extensao-universitaria-editado.pdf>. Acesso em: 22 dez. 2016.

FORPROEX. Fórum Nacional de Pró-Reitores de Extensão das Universidades Públicas Brasileiras. Documento Final do I Encontro de Pró-Reitores de Extensão das Universidades Públicas Brasileiras. UNB, Brasília, 1987. In: NOGUEIRA, M. das D. P. (org.). Extensão Universitária: diretrizes conceituais e políticas. Documentos básicos do Fórum de Próreitores de Extensão das Universidades Públicas Brasileiras. Belo Horizonte: PROEX/ UFMG; Fórum, 2000.

FORPROEX. Política Nacional de Extensão Universitária. 2012. Disponível em: <https://www.ufmg.br/proex/renex/documentos/2012-07-13-Politica-Nacional-deExtensao.pdf>. Acesso em: 22 dez. 2016.

FRAGA, L. S. Extensão e transferência de conhecimento: as Incubadoras Tecnológicas de Cooperativas Populares. 2012. 242f. Tese (Doutorado em Política Científica e Tecnológica) - Instituto de Geociências, Universidade Estadual de Campinas, 2012.

FREIRE, S. M. Extensão universitária e direitos humanos: desafios na contemporaneidade. Extensão em Foco, n. 2, p. 133-142, 2008.

GOERGEN, P. Tecnociência, pensamento e Formação na educação superior. Avaliação, v. 19, n. 3, p. 561-584, 2014.

LEHER, R. Para silenciar os campi. Educação e Sociedade, v. 25, n. 88, p. 867-891, 2004. 
LEHER, R.; VITTÓRIA, P.; MOTTA, V. C. Educação e mercantilização em meio à tormenta político-econômica do Brasil. Germinal: Marxismo e Educação em Debate, v. 9, n. 1, p. 14-24, 2017.

LOURENÇO, C. A. P.; AFONSO, M. L. M. Educação em direitos humanos no ensino superior: estratégias políticas, teóricas e metodológicas. Revista Competencia, v. 8, n. 1, 2015.

MAGENDZO, A. Educación en derechos humanos - un desafío para los docentes de hoy. Santiago: LOM Ediciones, 2006.

MARQUES, W. Expansão e oligopolização da educação superior no Brasil. Avaliação, v. 18, n. 1, p. 69-83, 2013.

MARTINS, A. L. M. A Marcha do "Capitalismo Universitário" no Brasil nos anos 1990. Avaliação, v. 13, n. 3, p. 733-743, 2008.

MINTO, L. W. A educação da miséria: particularidade capitalista e educação superior. 2011. 215 f. Tese (Doutorado em Educação) - Faculdade de Educação, Universidade Estadual de Campinas, Campinas, 2010.

OLIVEIRA, R. C. Educação Superior, Concepções e Função Social da Universidade, 2010.

PAULA, J. A. A extensão universitária: história, conceito e propostas. Interfaces - Revista de Extensão, n. 1, p. 05-23, jul./nov. 2013.

PIOVESAN, F. Ações afirmativas da perspectiva dos direitos humanos. Cadernos de Pesquisa, v. 35, n. 124, p. 43-55, jan./abr. 2005.

PIOVESAN, F. Educação em direitos humanos no ensino superior. ZENAIDE, M. de N. et al. A formação em direitos humanos na universidade: ensino, pesquisa e extensão. João Pessoa: UFPB, p. 71-81, 2005.

PIOVESAN, F.; FACHIN, M. G. Educação em Direitos Humanos no Brasil: desafios e perspectivas. Revista Jurídica da Presidência, v. 19, n. 117, p. 20-38, 2017.

RAMOS, A. de C. Curso de Direitos Humanos. Editora Saraiva, 2018.

ROSA, F. N. A docência na educação superior brasileira: bem público ou educaçãomercadoria? Revista Brasileira de Ensino Superior, v.2, n.3, p.58-66, 2016.

SALVIOLI, F. La universidad y la educación en el siglo XXI: los derechos humanos como pilares de la nueva Reforma Universitaria. Instituto Interamericano de Derechos Humanos. San José: IIDH, 2009.

SERAFIM, M. P. O processo de mercantilização das instituições de educação superior: um panorama do debate nos EUA, na Europa e na América Latina. Avaliação, v. 16, n. 2, p. 241-265, 2011.

SGUISSARDI, V. Educação Superior no Brasil: democratização ou massificação mercantil. Educação e Sociedade, v. 36, n. 133, p. 867-889, 2015.

SILVA, T. S. Extensão universitária, direitos humanos e cidadania: reflexões sobre a proposta de política de extensão e a prática na universidade federal. 2012. 243 f. Dissertação (Mestrado em Política Social) - Pós-Graduação em Política Social, Universidade Católica de Pelotas, Pelotas, 2012. 
SOUZA, A. L. L. A História da Extensão Universitária. Campinas: Editora Alínea, 2010.

TOSI, G. Direitos humanos como eixo articulador do ensino, da pesquisa e da extensão. ZENAIDE, M. de N. et al. A formação em direitos humanos na universidade: ensino, pesquisa e extensão. João Pessoa: UFPB, p. 22-41, 2005.

\section{NOTAS}

${ }^{1}$ Entende-se como direitos humanos, o conjunto de direitos historicamente constituídos, os quais visam proteger a dignidade da pessoa humana, de forma a garantir uma vida digna pautada nos princípios da liberdade, igualdade e dignidade. Tal conjunto de direitos é composto pelos direitos civis, políticos, econômicos, sociais e culturais, dentre outros (RAMOS, 2018).

${ }^{2}$ Para visualizar dados a respeito da composição do ensino superior brasileiro e do perfil do acesso, conferir em Sguissardi (2015) e Dagnino (2015).

${ }^{3} \mathrm{Na}$ verdade, acreditamos que Sguissardi (2015) conduz sua crítica àquelas visões que expressam relação simultânea e determinista entre a sociedade e a universidade.

${ }^{4}$ Há ainda, um terceiro ponto de vista, que pode ser considerado ultrapassado em âmbito teórico, mas que ainda é bastante forte na comunidade acadêmica (DAGNINO; DIAS, 2007): o de que a universidade cumpre sua função social na medida em que, isolada, produz conhecimento desinteressado que, através processos lineares de transferência, beneficiaria a sociedade como um todo.

${ }^{5}$ Não vamos, neste tópico, nos aproximar mais a fundo deste debate. $\mathrm{Na}$ verdade, elencamos a mercantilização como um dos fatores que dificultam à expansão da EDH nas universidades, pois, mesmo que ela não seja propriamente "contrária" ao mercado e à empresa, realizar processos de reflexão crítica, pesquisa e extensão em EDH em universidades públicas cada vez mais voltadas à interesses utilitário-produtivos-operacionais torna-se um desafio crescente.

${ }^{6} \mathrm{O}$ Pacto parte do reconhecimento das Instituições de Ensino Superior como lócus da construção e disseminação de conhecimentos para a construção de uma cultura pautada nos princípios dos direitos humanos. À vista disso, seu processo de elaboração contou com uma consulta pública do texto, de modo a permitir que a sociedade civil organizada, representada por meio de tais Instituições, pudessem contribuir com seu aperfeiçoamento.

${ }^{7}$ Num panorama global, os processos de aproximação cada vez mais simbióticos com o mundo produtivo e com o mercado, emulando inclusive seu padrão administrativo, são sustentados ideologicamente pela ideia de que as universidades deveriam guiarse sobretudo à oferecer conhecimento e formação úteis a um mercado pautado pela dita "economia do conhecimento" (DIAS SOBRINHO, 2013; 2014; GORGEN, 2014; DAGNINO, 2015). Soma-se a isso a noção de que o ensino superior deveria fragmentarse em organizações especializadas que, preferencialmente, venderiam serviços educacionais direcionados a públicos-alvo e segmentos específicos; e as universidades, especialmente, deveriam tornar mais eficiente sua gestão, flexibilizar os currículos e comercializar o conhecimento produzido. Nesse aspecto, apresenta-se o chamado capitalismo acadêmico, 
caracterizado pelo fortalecimento dos discursos acerca do empreendedorismo e inovação nas universidades e por maior engajamento na comercialização do conhecimento e pela busca por autofinanciamento diante da diminuição ou estagnação dos recursos públicos às universidades (DIAS; SERAFIM, 2015).

Submetido: 06/06/2018

Aprovado: 07/09/2018

Contato:

Thais Aparecida Dibbern

Universidade Estadual de Campinas (Unicamp) Faculdade de Ciências Aplicadas (FCA) - Campus Limeira

Rua Pedro Zaccaria, 1300 - Limeira, São Paulo

Limeira $|\mathrm{SP}|$ Brasil

CEP 13.484-350 